\title{
Is it Time for an Updated 'Eco-Evo-Devo' Definition of Evolution by Natural Selection?
}

\author{
Marion Blute*
}

\begin{abstract}
A lot of science has passed under the bridge since the classic definition of evolution as a change in gene frequencies in a population became common. Much knowledge has accumulated since then about evolution, heredity, ecology, development, phenotypic plasticity, niche construction and genetic drift. Building on Van Valen's description of evolution as "the control of development by ecology," it is suggested that the classic definition be replaced by a updated 'eco-evo-devo' definition of evolution by natural selection which acknowledges this accumulation.
\end{abstract}

Population genetics has long defined evolution as a change in gene, or more accurately, allele frequencies in a population. While this definition undoubtedly emerged from the development of population genetics in the 1920s and 30s, its actual origin is obscure (Mayr 1982, 400). In any event, a lot of science has passed under the bridge since it became common, suggesting that it may be time for an update.

Many theories of speciation have been formulated in population genetics terms - theories invoking geographical isolation, ecological isolation or sexual selection whether alone, or in varying combinations and orders (Coyne 2004). However, it is obvious that "a change in allele frequencies in a population" does not directly address speciation or evolution beyond the species level. Hence it would be more accurate to say what everyone means now-that "microevolution is" etc. in a definition.

The meaning of the word "gene" has changed historically (Beurton, et al. 2000; Rheinberger and Muller-Willie 2004) and also varies currently among biologists as survey research has shown (Stotz, et al. 2004). This is so much the case that some biologists have taken to blogging about it (Moran 2007; http://sandwalk.blogspot.com/2007/01/what-is-gene.html). The evolutionary gene of population genetics, "that which segregates and recombines with appreciable frequency" (Williams 1966, 24) or "any hereditary information for which there is a favorable or unfavorable selection bias equal to several or many

\footnotetext{
* Marion Blute is an associate professor of Sociology at the University of Toronto at Mississauga. She has published in a variety of life and social science journals on biological, sociocultural and gene-culture coevolutionary topics and teaches theory to undergraduate and graduate students. She is currently working on a SSHRC-funded project in science studies and on a monograph on Darwinian Sociocultural Evolution: Evolutionary Solutions to Problems in Cultural and Social Theory.
}

Spontaneous Generations 2:1 (2008). ISSN 1913-0465. University of Toronto 
times its rate of endogenous change" (Williams 1966, 25) does not coincide with the molecular biological classic gene as that segment of a DNA molecule coding for a single strand of a protein molecule, or with the contemporary definition of an ORF (open reading frame) for example. The crux of the problem, that genetic units of structure, function, mutation, replication and recombination do not necessarily coincide, needs to be accommodated, perhaps by viewing the nucleoid/nucleus as the brain/government respectively of a cell rather than as a God-like ghost in the machine which came first, is all powerful and for which all else exists (Blute 2005). In the context of a definition of evolution by natural selection, it might best be accomplished by speaking, as do Burt and Trivers (2006) in their monograph on intragenomic conflict for example, of genomic "elements" or sequences rather than genes. It is also now understood that heredity can be "epigenetic" as well as genetic (reviewed in Jablonka and Lamb 2005, Chpt. 4), although issues remain concerning the longer-term stability of inherited cytosine methylation for example. Together these suggest that it would be more prudent to speak of a change in the frequency of "hereditary elements" in a definition which would cover both what is known currently, as well as what may be revealed in the future. For example, on the assumption that history normally leaves traces in evolution, if there ever was an RNA world, it is possible, perhaps even likely, that traces of such a world in the form of autocatalytic RNAs will eventually be found lurking in some or all extant organisms.

As has been widely discussed, the traditional definition includes heredity and evolution but omits ecology and development. Van Valen (1973) began the rectification of this by famously declaring that, "evolution is the control of development by ecology." The fact is that no selection pressure ever works solely as a sieve, filter or sorting device. Rather it can work in one of the following two ways.

First, an ecological change induces some individual(s) of a preexisting hereditary background to develop differently morphologically, physiologically or behaviorally relative to others (possible because of extensive phenotypic plasticity, [Pigliucci 2001]), thus changing relative fitnesses, and hence ultimately the frequencies of hereditary elements. If a new food source becomes available and is made good use of by some individuals which are hereditably different than others, the former are not simply chosen; they are changed. They may be induced by their altered nutritional status to grow bigger, live longer, move faster/further, or develop in a more adaptively plastic way; they may be induced to be more fecund, produce offspring which grow bigger, live longer, move faster/further, or develop in a more adaptively plastic way. Similarly, a new antagonist like a parasite or predator does not bloodlessly choose; it mutilates. Selection in other words does not work in a "backward" direction-sieving, filtering or sorting. Rather, it works inductively in a "forward" direction, altering the flesh and blood of living organisms. This is why it alters relative fitnesses and ultimately, therefore, the frequencies of hereditary elements. 
It would be incorrect to attribute the change to the hereditary elements involved, which might have been around for who knows how long doing who knows what in a different ecologically inductive environment, even though they are in fact responsible for the variation. In short, because selection pressures act inductively, but in a fashion that discriminates among different norms of reaction, evolutionary change can be, and commonly is initiated phenotypically, without invoking Lamarckianism. Neither does this require Waddington's genetic assimilation, the Baldwin effect, or West-Eberhard's (2003) phenotypic and genotypic accommodation. Because a priori, such an ecological change acting inductively is no more or no less likely to be adaptive than traditional genetic mutations or recombinants, this form of selection conforms strictly to the fundamental neo-Darwinian insight that adaptation is achieved, not because it is sought by individuals, but because selection controls what evolves in populations. Similarly a priori, such changes are no more or no less likely than traditional genetic mutations or recombinants to require additional heritable change or variation to assimilate, accommodate or stabilize the change.

Secondly and in one sense more conventionally, the reverse can take place. A hereditary change like a genetic mutation or recombination leads some individual(s) to develop morphologically, physiologically or behaviorally in such a way relative to others that they perceive, define or construct a preexisting feature of the ecological environment differently, thus changing relative fitnesses, and hence ultimately the frequencies of hereditary elements. If a new hereditary element becomes available enabling its carriers to consume and make good use of an unutilized resource, the ecological environment is changed. That change in turn again does not simply sieve, filter, or sort but inductively alters the affected organisms improving their nutritional status, resulting ultimately in a change in gene frequencies. Less conventionally however, this implies that niche construction (Odling-Smee et. al. 1996; 2003) is not some occasional phenomenon; rather, it is the means through which all evolutionary change initiated genetically is achieved.

There exist several classifications of modes of selection, including natural versus artificial, natural versus sexual, and stabilizing, directional or disruptive. An additional fundamental distinction which needs to be recognized is whether selection is initiated exogenously (inductive-type selection) or endogenously (constructive-type selection). However, whether by means of an ecological change against an existing variety of hereditary backgrounds or a hereditary change against an existing ecological background, or even, but presumably more rarely, both simultaneously-evolutionary change is never wrought by anthropomorphized natural selectors. It is always wrought by inductive and/or constructive causal interactions between ecology and morphology, physiology or behavior-mediated by inheritance. Drift works via the same two initial mechanisms, also ultimately altering the frequencies of hereditary elements in a 
population, but for stochastic rather than adaptive reasons. Hence the final definition suggested which contains the minimal number of changes required to be consistent with current knowledge is:

Microevolution by natural selection is any change in the inductive control of development (whether morphological, physiological or behavioral) by ecology and/or in the construction of the latter by the former which alters the relative frequencies of hereditary elements in a population beyond those expected of randomly chosen variants.

\title{
Acknowledgements
}

I thank the Social Sciences and Humanities Research Council of Canada for research support, Gail Greer and attendees at the session on theoretical integration of the 2007 ISHPSSB conference for their comments.

\author{
MARION BLUTE \\ Department of Sociology \\ The University of Toronto \\ at Mississauga \\ marion.blute@utoronto.ca
}

\section{References}

Beurton, P. J., R. Falk and H. Rheinberger. 2000. The Concept of the Gene in Development and Evolution: Historical and Epistemological Perspectives. Cambridge: Cambridge University Press.

Blute, M. 2005. If the Genome Isn't a God-like Ghost in the Machine, then What Is It? Biology and Philosophy 20: 401-407.

Burt, A., and R. Trivers. 2006. Genes in Conflict: The Biology of Selfish Genetic Elements. Cambridge, MA: The Belknap Press of Harvard University Pres.

Coyne, J. A. 2004. Speciation. Sunderland, MA: Sinauer Associates.

Jablonka, E. and M. J. Lamb. 2005. Evolution in Four Dimensions: Genetic, Epigenetic, Behavioral, and Symbolic Variation in the History of Life. Cambridge, MA: MIT Press.

Mayr, E. 1982. The Growth of Biological Thought: Diversity, Evolution and Inheritance. Cambridge, MA: The Belknap Press of Harvard University Press.

Moran, L. A. 2007. What is a Gene? http://sandwalk.blogspot.com/2007/01/what-is-gene.html

Odling-Smee, J., K. N. Laland and M. Feldman. 1996. Niche Construction. The American Naturalist 146: 641-648.

Odling-Smee, J., K. N. Laland, and M. Feldman. 2003. Niche Construction: The Neglected Process in Evolution. Princeton: Princeton University Press.

Pigliucci, M. 2001. Phenotypic Plasticity: Beyond Nature and Nurture. Baltimore: Johns Hopkins University Press. 
Rheinberger, H. J. and S. Müller-Willie. 2004. Gene. Stanford Encyclopedia of Philosophy. http://plato.stanford.edu/entries/gene/

Stotz, K., P. E. Griffiths and R. D. Knight. (2004) How Biologists Conceptualize Genes: An Empirical Study. Studies in the History and Philosophy of Biological and Biomedical Sciences 35:647-673.

Van Valen, L. 1973. Fetschrift. Science 180: 488.

West-Eberhard, M. J. 2003. Developmental Plasticity and Evolution. New York: Oxford University Press.

Williams, G. C. 1966. Adaptation and Natural Selection: A Critique of Some Current Evolutionary Thought. Princeton: Princeton University Press. 